\title{
INVENTÁRIO DE BARREIRAS E FACILITADORES AO EMPREENDEDORISMO: CONSTRUÇÃO E VALIDAÇÃO DE UM INSTRUMENTO
}

\author{
Gustavo Henrique Silva de Souza* \\ souza.g.h.s@gmail.com \\ Jorge Artur Peçanha de Miranda Coelho*** \\ jorge.coelho@famed.ufal.br \\ Germano Gabriel Lima Esteves*** \\ germanoesteves@unirv.edu.br \\ Nilton Cesar Lima***** \\ niltoncesar@facic.ufu.br \\ Paulo da Cruz Freire dos Santos** \\ paulodacruzfreire@gmail.com \\ *Instituto Federal do Norte de Minas Gerais \\ **Universidade Federal de Alagoas \\ ***Universidade de Rio Verde \\ *****Universidade Federal de Uberlândia
}

http://dx.doi.org/10.1590/1413-2311.04315.57744

Recebido em 10/08/2015

Aprovado em 23/08/2016

Disponibilizado em 31/01/2017

Avaliado pelo sistema "double blind review"

Revista Eletrônica de Administração

Editora-chefe: Aurora Zen

ISSN 1413-2311 (versão "on line")

Editada pela Escola de Administração da Universidade Federal do Rio Grande do Sul.

Periodicidade: Quadrimestral

Sistema requerido: Adobe Acrobat Reader

\section{RESUMO}

A identificação do comportamento empreendedor vem encontrando dificuldades de mensuração, uma vez que os resultados e instrumentos, até então desenvolvidos, não têm apresentado um modelo comportamental de compatibilidade universal para o empreendedor e não têm seguido algumas recomendações encontradas na literatura para a pesquisa em empreendedorismo, considerando elementos circunstanciais e comportamentais. Nesse sentido, visando preencher essa lacuna, este artigo reporta um estudo sobre a construção e validação do Inventário de Barreiras e Facilitadores ao Empreendedorismo, composto por 8 subescalas independentes que mensuram as seguintes facetas: Intenção de Empreender; Risco; Acesso à Capital; Inovação; Oportunidade; Liderança e Gerenciamento; Rede de Relacionamento; Paixão. O estudo parte da premissa de que o indivíduo se depara com Barreiras e Facilitadores, de ordem comportamental e contextual (fatores sociais, econômicos e ambientais), que podem impelir ou inibir a ação de empreender. Por meio de técnicas de 
validação, chegou-se a um instrumento de baixo custo (lápis e papel) e de fácil aplicação (autorrelato), com parâmetros psicométricos adequados.

Palavras-chave: Comportamento Empreendedor; Inventário; Barreiras; Facilitadores; Empreendedorismo.

\title{
INVENTORY OF BARRIERS AND FACILITATORS TOWARDS THE ENTREPRENEURSHIP: CONSTRUCTION AND VALIDATION OF AN INSTRUMENT
}

\begin{abstract}
The identification of entrepreneurial behavior has finding difficulty to measure it, since the results and instruments developed so far, have not shown a behavioral model of universal compatibility for the entrepreneur and not have followed some recommendations from the literature for the research on entrepreneurship, considering circumstantial and behavioral elements. In this sense, aiming to fill this gap, this work reports a study on the construction and validation of the Inventory of Barriers and Facilitators towards the Entrepreneurship, which consists of 8 independent subscales that measure the following facets: Entrepreneurial Intention; Risk; Access to capital; Innovation; Opportunity; Leadership; Relationship network; Passion. The study assumes that the individual is faced with Barriers and Facilitators of behavioral and contextual order (social and environmental) which can propel or inhibit the action of entrepreneurship. By validation techniques, we reached a low-cost instrument (pencil and paper) and easy to apply (self-report) with good psychometric properties.
\end{abstract}

Keywords: Entrepreneurial Behavior; Inventory; Barriers; Facilitators; Entrepreneurship.

INVENTARIO DE BARRERAS Y FACILITADORES PARA EL EMPRENDIMIENTO: CONSTRUCCIÓN Y VALIDACIÓN DE UN INSTRUMENTO

\section{RESUMEN}

La identificación del comportamiento emprendedor viene encontrando algunas dificultades en medir, ya que los resultados y los instrumentos desarrollados hasta ahora no han mostrado un modelo de comportamiento de compatibilidad universal para el empresario y no han seguido algunas recomendaciones de la literatura para la investigación sobre el emprendimiento, teniendo en cuenta los elementos circunstanciales y de comportamiento. En este sentido, con el objetivo de llenar este vacío, este trabajo reporta un estudio sobre la construcción y validación del Inventario de Barreras y Facilitadores para el Emprendimiento, que consta de 8 sub-escalas independientes que miden las siguientes facetas: Intención de Emprender; Riesgo; Acceso al capital; Innovación; Oportunidad; Liderazgo y Gestión; Red de relaciones; Pasión. El estudio supone que el individuo se depara con barreras y facilitadores de orden de comportamiento y contextual (social y ambiental) que puede impulsar o inhibir la acción de emprender. A través de técnicas de validación, se llegó a un instrumento de bajo costo (lápiz y papel) y fácil de aplicar (auto-informe), con buenas propiedades psicométricas.

Palabras-clave: Comportamiento Empresarial; Inventario; Barreras; Facilitadores; Emprendimiento. 


\section{INTRODUÇÃO}

As teorias do empreendedorismo são consensuais ao conceber este fenômeno como um comportamento singular - com traços e características idiossincráticas -, que tipificam o indivíduo empreendedor e o diferencia das demais pessoas (SCHUMPETER, 1961; MASLOW, 1965; MCCLELLAND, 1972; SHAPERO; SOKOL, 1982; ROTTER, 1990; DRUCKER, 1993; MINER, 1997a; MUELLER; GOIĆ, 2002; SHANE, 2003). Apesar disso, argumenta-se que ainda não há resultados que fundamentem um modelo comportamental universal para o empreendedor (SANTOS, 2008), uma vez que os constructos relacionados a esse comportamento mudam à medida que pesquisas são realizadas em ambientes e culturas diferentes (MINER, 1997b; KRISTIANSEN; INDARTI, 2004; ALVES; BORNIA, 2011).

Por outro lado, os instrumentos de mensuração de características e traços empreendedores (e.g., MCCLELLAND, 1972; CARLAND; CARLAND; HOY, 1992, 1998; KRISTIANSEN; INDARTI, 2004; LOPES JUNIOR; SOUZA, 2005; GONÇALVES FILHO VEIT; GONÇALVES, 2007; SANTOS, 2008; SOUZA et al., 2013) têm apresentado limitações psicométricas. O instrumento de McClelland (1972) que identifica características comportamentais de empreendedores, por exemplo, não atende a parâmetros psicométricos, nem a critérios de construção de medidas (ver, PASQUALI, 2010), o que torna a sua usabilidade limitada. A Carland Entrepreneurship Index (CARLAND; CARLAND; HOY, 1992, 1998) também apresenta limitações devido ao seu modelo de resposta dicotômica (ver, MAcCALLUM et al., 2002), restringindo o leque de análises para a verificação dos padrões de validade (ver, NUNNALLY; BERNSTEIN, 1995), além de reportar dados inadequados pelo uso indevido da análise de componentes principais em itens dicotômicos, uma vez que deveria ter utilizado a matriz de correlação tetracórica (ver, TABACHNICK; FIDELL, 2007). Por sua vez, a escala de Gonçalves Filho, Ceit e Gonçalves (2007) tem seu uso recomendado com base em índices insipientes de qualidade de ajuste $\left(\chi^{2} / \mathrm{gl}=3,51\right.$; GFI $=0,87$; AGFI = 0,85; CFI = 0,83), obtidos por meio de análise fatorial confirmatória (ver, KLINE, 2011).

Basicamente, não há um instrumento de identificação de perfil empreendedor que apresente parâmetros psicométricos adequados, apresentando validade fatorial, de constructo e de critério, como recomenda Pasquali (2010). De tal modo, este estudo tem o objetivo de construir e validar o Inventário de Barreiras e Facilitadores ao Empreendedorismo (IBFE).

Mensurar Barreiras e Facilitadores é coerente com as recomendações de Sarasvathy (2004), que alerta para uma reformulação nos estudos sobre empreendedorismo, de modo que se compreenda a composição do comportamento empreendedor sob a influência de 
circunstâncias que se assumem como Barreiras ou Facilitadores. Seguem-se os aspectos comportamentais do empreendedor e a proposição constitutiva das Barreiras e Facilitadores, para que se possa, então, operacionalizar o instrumento proposto.

\section{BASE CONCEITUAL}

\subsection{Aspectos do Empreendedor}

Embora pesquisas recentes em todo o mundo venham discutindo o 'perfil empreendedor' sob a perspectiva do indivíduo, isto é, uma série de características comportamentais intrínsecas ao indivíduo que o tornam empreendedor (e.g., GELDEREN et al., 2008; SCHMIDT; BOHNENBERGER, 2009; OBSCHONKA; SILBEREISEN; SCHMITT-RODERMUND, 2010; TAJEDDINI; ELG; TRUEMAN, 2013; ROXAS; CHADEE, 2013); a ação de empreender configura um continuum de comportamentos (fatores individuais) e contextos (fatores sociais e ambientais) que tornam um indivíduo potencialmente empreendedor em empreendedor (SARASVATHY, 2004; BARBASÁNCHEZ; ATIENZA-SAHUQUILLO, 2012; CARDON et al., 2013).

Considerando a definição geral de Hisrich, Peters e Shepherd (2014), o empreendedor é alguém que cria algo novo, com valor agregado, e que, portanto, enfrenta riscos financeiros, sociais e psíquicos; visando chegar a uma determinada recompensa, manifestada em formato de satisfação e independência econômica e social. Drucker (1993) corrobora essa linha de pensamento, defendendo que o empreendedor é aquele que se posiciona frente à realidade (riscos, restrições e desafios) para convertê-la em oportunidade, visando resultados e lucros.

\subsection{Definição constitutiva das Barreiras e Facilitadores ao Empreendedorismo}

Segundo a proposta de Sarasvathy (2004), Alencar (2010) e Crouse, Doyle e Young (2011), as Barreiras impedem ou interrompem uma ação, enquanto os Facilitadores motivam (incentivam) ou sustentam uma ação. Para o problema do empreendedorismo, Sarasvathy (2004, p. 709) argumenta que "a remoção das barreiras podem promover mais e melhor o empreendedorismo do que quaisquer incentivos". Por suposto, o indivíduo se depara com Barreiras e Facilitadores, de ordem comportamental e contextual (fatores sociais, econômicos e ambientais), que impelem ou inibem a ação de empreender.

Considera-se que o indivíduo pode vir a ter potencial empreendedor, suportado por uma série de Facilitadores (por exemplo, estilo de liderança) que o favorecem a empreender, mas ao coexistirem às Barreiras (por exemplo, ausência de suporte financeiro ou indisposição aos riscos de um negócio) que assumem o papel de regulação ou trava das ações, indicando algum tipo de perda ou ônus para o indivíduo, a ação de empreender é inibida. Desta forma, as Barreiras e os Facilitadores atuam conjuntamente na explicação da ação empreendedora. 
Embora Barreiras e Facilitadores podem abarcar diversos constructos [personalidade, valores, atitudes etc.] (CROUSE; DOYLE; YOUNG, 2011), no campo do empreendedorismo as Barreiras e Facilitadores agem como constructo circunstancial (SARASVATHY, 2004) e, por isso, neste tipo de medida não são incluídos fatores ligados, por exemplo, à personalidade [como lócus de controle e persistência] (ver, BRANDSTÄTTER, 2011) ou aos valores [como, êxito, prestígio e poder] (ver, GOUVEIA; MILFONT; GUERRA, 2014).

\subsubsection{Intenção de Empreender}

Unanimemente, a Intenção de Empreender é o atributo catalisador do comportamento empreendedor (FRANKE; LÜTHJE, 2004; GELDEREN et al., 2008; OBSCHONKA; SILBEREISEN; SCHMITT-RODERMUND, 2010; ABEBE, 2012). Kristiansen e Indarti (2004) explicam que a intenção de empreender é uma predisposição do indivíduo aos negócios, formada por 3 elementos: (1) fatores demográficos e individuais [gênero, idade, nível educacional e experiências de trabalho]; (2) personalidades e atitudes [necessidade de realização, lócus de controle e autoeficácia]; e, (3) elementos contextuais [acesso à capital, acesso à informação e redes sociais].

Portanto, a intenção só se tornará ação se houver a sobreposição de facilitadores sobre as barreiras. Isto é, um indivíduo que possui a intenção de empreender em maior medida, é um empreendedor em potencial, independente de oportunidades lucrativas ou possibilidades de sucesso [Facilitador], enquanto que, outros indivíduos podem ter a intenção de empreender apenas sob as condições de lucro ou sucesso [Barreira].

\subsubsection{Paixão}

Diversos motivadores levam um indivíduo a empreender, em geral, associados a algum tipo de necessidade (MASLOW, 1965). Como atributo da necessidade de realização, a Paixão tem sido considerada um dos motivadores centrais do empreendedorismo, destacandose entre muitos estudos sobre o empreendedor (e.g., MA; TAN, 2006; LOCKE; BAUM, 2007; RAUCH; FRESE, 2007; CARDON, 2008; BARLACH, 2011; LAAKSONEN; AINAMO; KARJALAINEN, 2011; LUNA, 2012; CARDON et al., 2013). Para Dornelas (2004), o empreendedor é um indivíduo que não quer ser igual aos seus pares e possui uma motivação singular: é apaixonado pelo que faz. Ou, como Bygrave (2004) afirma, o empreendedor é um indivíduo dedicado e devoto ao trabalho.

Cardon et al. (2005) sugerem que a atividade empreendedora está intimamente relacionada à emoção, apesar de aspectos emotivos serem negligenciados no contexto empresarial e gerencial. Para os autores, comumente, empresários tratam seus negócios como algo pessoal, se apegam ao negócio, e sentem que o negócio é como se fosse, 
metaforicamente, um 'bebê' ou um 'filho'. Esse sentimento de paternidade, segundo os autores, levam os empreendedores a nutrirem uma prevalente paixão pelo próprio negócio.

Para Locke e Baum (2007) e Mathieu e St-Jean (2013), o empreendedor possui uma paixão egoista e narcisista, que o motiva a lutar pelo desenvolvimento do próprio negócio. Para esses autores, a motivação é um mediador de características individuais relacionadas à perseverança, visão, independência, necessidade de realização e paixão.

Compreende-se que a predisposição a se apaixonar pelo próprio trabalho é um aspecto que incentiva o surgimento do empreendedor [Facilitador], no entanto, um empreendimento exige dedicação extrema e demasiado envolvimento pessoal [Barreira], isto é, independente de se satisfazer com o que faz, é necessário que o empreendedor mantenha o negócio, mesmo que tenha que viver exclusivamente para o seu negócio.

\subsubsection{Fácil Acesso Instrumental / Rede de Relacionamentos}

Segundo Kristiansen e Indarti (2004, p. 64), o fácil acesso à capital (dinheiro) ou equipamentos e recursos "é um preditor positivo significativo da intenção empreendedora". Ideia compartilhada por Brush, Greene e Hart (2002), que afirmam ser capital e recursos os principais itens de apoio para o desenvolvimento de um empreendimento.

No entanto, Sheng (2008) defende que não adianta apenas ter capital (dinheiro), mas sim, a facilidade de se conseguir capital. $\mathrm{O}$ autor demonstra que a facilidade de obtenção de mercadorias, financiamento e recursos, por meio de redes de relacionamento formais e informais, motiva empreendedores a iniciarem seus próprios negócios.

É notório que muitos estudiosos vêm defendendo vigorosamente a questão de que o empreendedor possui ou deve possuir boas redes de relacionamento, pois, as parcerias são essenciais para o desenvolvimento de qualquer negócio. Shapero e Sokol (1982) foram os pioneiros a definirem o papel do empreendedor como um indivíduo social. Outros autores corroboram essa linha de pensamento e trazem termos variados que influem em uma determinação ampla para o 'social'. Kristiansen e Indarti (2004), em uma visão mais sistêmica e gerencial, expõem que o empreendedor está inserido em redes sociais em busca de parceiros e aliados estratégicos. Nassif, Ghobril e Silva (2010) apontam a capacidade de comunicação como característica fundamental do empreendedor para realizar parcerias.

Nos últimos anos, Santos (2008) levantou que o empreendedor constrói redes de relações formais e informais para a concretização de seus objetivos pessoais e empresariais. Para isso, o empreendedor torna-se ou é - em essência -, segundo Schmidt e Bohnenberger (2009), um indivíduo sociável e/ou extrovertido.

\subsubsection{Estilo de Liderança / Habilidades de Gerenciamento / Oportunidades}

REAd | Porto Alegre - Edição 85 - N 3 - Setembro / Dezembro 2016 - p. 381 - 412 
Elementos interdependentes relacionados aos aspectos valorativos e traços disposicionais, comumente, caracterizados dentro das necessidades de realização, como, querer ter o próprio negócio, querer ter muito dinheiro, querer ser o chefe [mandar], buscar autocontrole e autoeficácia, ser ambicioso, persistente, obstinado e decidido e não aceitar fracasso, em geral, são fatores subjacentes ao desenvolvimento de um perfil específico dentre indivíduos potencialmente empreendedores: o estilo de liderança (MUELLER; GOIĆ, 2002; MARKMAN; BARON, 2003; LOPES JUNIOR; SOUZA, 2005; MARKMAN; BARON; BALKIN, 2005; SCHMIDT; BOHNENBERGER, 2009; BARLACH, 2011; MORAES; HASHIMOTO; ALBERTINI, 2013). Outras abordagens associam especificamente o estilo de liderança do empreendedor a traços de narcisismo (MATHIEU; ST-JEAN, 2013) e de lócus de controle interno (MINER, 2000; MUELLER; THOMAS, 2001).

$\mathrm{O}$ estilo de liderança é um atributo essencial do empreendedorismo, que o empreendedor adquire devido as suas preferências, necessidades e traços de personalidade (MUELLER; GOIĆ, 2002; MARKMAN; BARON, 2003; FILION, 2004; KARABEY, 2012). É possível pontuar que o estilo de liderança é um dos fatores decisivos que induzem um indivíduo empreender, isto é, ser líder e não liderado.

Dentro dessa linha de pensamento, autores como Drucker (1993), Miner (2000), Guiso e Schiavardi (2005) e Santos (2008) sugerem que o empreendedor possui habilidades que permeiam a disciplina [foco e prioridades], a objetividade [metas e economia], o planejamento [conhecimento e ações intencionais e coordenadas], a flexibilidade [articulação e maleabilidade], a resolução de problemas [senso criativo e imaginação] e a comunicação persuasiva [negociação e aquisição]. Tais habilidades, apesar de encontradas em diferentes graus entre empreendedores, são sempre atributos da capacidade individual do empreendedor.

Assim, compreende-se que o perfil empreendedor engloba também certas habilidades de gerenciamento que estão interligadas ao estilo de liderança. Isto é, o empreendedor possui aspectos psicológicos e comportamentais que o levam a um perfil de líder e de centralizador, o que implica na aquisição de habilidades de gerenciamento. Além das habilidades de gerenciamento, segundo Santos (2008), há aspectos nos empreendedores que surgem devido à habilidade de resolução de problemas - implícitos o senso criativo e a aquisição de informações -, que é a identificação e valoração das oportunidades (ver, SHANE, 2003).

Especificamente, a oportunidade empreendedora (entrepreneurial opportunity), como definem Sarasvathy et al. (2003), é a existência de uma conjuntura de fatores - pessoais, contextuais, mercadológicos etc. -, que são favoráveis e adequados para a criação ou desenvolvimento de um negócio ou produto/serviço que possua valor econômico. 
Além disso, pesquisas têm indicado o 'senso de oportunidade' como um atributo social em seu papel para a geração de novos negócios (ZAHRA et al., 2008; BOSZCZOWSKI; TEIXEIRA, 2012). A oportunidade está relacionada intimamente (nexus) com o postulado histórico do indivíduo, isto é, as oportunidades, em geral, têm ligação com o empreendedor e com a sua vida e o contexto com o que o indivíduo passa ou passou, tendo importância na trajetória do empreendedor para alcançar o sucesso do negócio (SARASON; DEAN; DILLARD, 2006; SANTOS-ÁLVAREZ; GARCÍA-MERINO, 2010).

De tal modo, defende-se que a oportunidade não só deve ser identificada e valorada, mas deve ser explorada. Isso porque, o empreendedor possui aguçado senso de oportunidade (SHANE, 2003). O ciclo de identificação, valoração e exploração da oportunidade também é chamado de processo de internalização do negócio, isto é, um processo em que o empreendedor internaliza todas as coisas para encontrar e empreender oportunidades: vive em estado de alerta, é o próprio centro de interesse, utiliza-se da lógica causal e de experiências prévias - o meio em que o empreendedor está e suas redes sociais (CASSON, 2005; CORBETT, 2005; PARK, 2005; CASSAR, 2006; CHOI; LÉVESQUE; SHEPHERD, 2008; HARMELING; SARASVATHY; FREEMAN, 2009; UCBASARAN; WESTHEAD; WRIGHT, 2009; SANTOS-ÁLVAREZ; GARCÍA-MERINO, 2010).

Porém, uma das contribuições que mais marcaram a oportunidade empreendedora foi o trabalho de Nicolaou, Shane, Cherkas e Spector (2009). Os autores descobriram que os mesmos marcadores genéticos contribuem para a identificação e valoração da oportunidade e a tendência do indivíduo em ser empreendedor ( $\mathrm{n}=1706$ pares de gêmeos). Os autores descobriram que o senso de oportunidade é um atributo de herança genética, sendo $53 \%$ da correlação (positiva) entre oportunidade e empreendedorismo advindo de uma etiologia genética comum. Os mesmos autores descobriram posteriormente (SHANE et al., 2010), que marcadores genéticos são responsáveis por parte da covariância entre as características de personalidade e a tendência a ser empreendedor $(n=4712$ pares de gêmeos).

\subsubsection{Inovação/ Criatividade / Risco}

Com efeito, uma das características individuais do empreendedor mais antigas (CANTILLON, 1755) e difundidas (DRUCKER, 1993) é a Inovação. Drucker (1993) sustenta que os empreendedores são essencialmente inovadores. A inovação em si é o principal instrumento que o empreendedor se utiliza para explorar ou executar um negócio. Santos (2008) enfatiza que o empreendedor se envolve pessoalmente com processos de inovação, que transpassam o ambiente empresarial e são visualizados também em sua vida. 
A inovação é subsidiada pela habilidade do empreendedor de visualizar oportunidades, criar redes e tirar vantagem delas. Para isso, o empreendedor se envolve com novas possibilidades produtivas ou avanços tecnológicos, tendo a capacidade de identificar onde e como pode ser criado ou fomentado um novo mercado para suas inovações (PARK, 2005). Nesse viés, Mueller e Thomas (2001) assumem que o empreendedor não só reconhece a importância da inovação, mas é o próprio agente ativo da inovação, gerando e selecionando as melhores ideias, implementando e transformando-as em negócios, visando garantir resultados.

Alguns autores, por sua vez, associam à inovação alguns aspectos do empreendedor, como: conhecimento específico do mercado e da área do negócio [produtos, serviços, potencialidades etc.] (BRUSH; GREENE; HART, 2002; WU; WU, 2008; NASSIF; GHOBRIL; SILVA, 2010); visão, iniciativa, sensibilidade [insights], prospecção, imaginação e criatividade [talento natural] (DORNELAS, 2004; SCHMIDT; BOHNENBERGER, 2009); ter propensão à criação, fazer coisas, agir, desenvolver (TAJEDDINI; ELG; TRUEMAN, 2013); e, ter a capacidade e competência de detectar e aproveitar novas oportunidades, mesmo assumindo riscos (KRISTIANSEN; INDARTI, 2004; SCHMIDT; BOHNENBERGER, 2009; BOSZCZOWSKI; TEIXEIRA, 2012; KARABEY, 2012).

Em uma perspectiva mais aguçada, Schmidt e Bohnenberger (2009) propõem que um elemento diretamente ligado à Inovação é a Criatividade. Associada conceitualmente à inovação como um atributo anterior, a criatividade deve ser analisada separadamente e complementarmente, porque é o ponto chave para os outros fatores da inovação como a imaginação e a sensibilidade, e porque é um atributo que surge através da confluência de 6 fatores distintos e interrelacionados: inteligência; estilo intelectual; conhecimento; personalidade; motivação; e, contexto ambiental (ALENCAR, 2010).

Nesse sentido, Drucker (1993) analisa que quando o indivíduo inova e é criativo, ele passa por uma série de resistências de aceitação de sua inovação em relação a outrem, e em termos de negócios, isso significa o sucesso ou o fracasso empresarial. Para que o indivíduo consiga ou queira passar por essa situação, em geral, ele tem que se sentir motivado ou disposto a arriscar. Ou seja, inovar é algo arriscado. Porém, toda a atividade econômica também é arriscada. O empreendedor é aquele que tenta definir e delimitar os seus riscos.

Por sua vez, estar disposto a arriscar é um comportamento que envolve a predominância de aspectos afetivos, como ambição, persistência, obstinação, paciência, otimismo, coragem, perseverança, ousadia e não aceitar o fracasso (NASSIF; GHOBRIL; SILVA, 2010). De tal modo, Moraes, Hashimoto e Albertini (2013) impõem uma ressalva ao 
comportamento empreendedor de estar disposto ao risco, que é justamente a aplicabilidade calculada do risco, isto é, assumir riscos calculados.

Por outro lado, o medo ou aversão ao risco inibe o posicionamento de um indivíduo a empreender (SANTOS, 2008). Como designam Moraes, Hashimoto e Albertini (2013), o empreendedor é alguém que assume riscos, mesmo os riscos calculados ou os riscos inerentes ao negócio, que balizam o acionamento comportamental, tal como um regulador. Logo, indivíduos que tem predisposição a correr riscos enfatizam este atributo como um Facilitador, enquanto que, indivíduos que tem aversão ao risco enfatizam este atributo como uma Barreira.

\section{MÉTODOS}

\subsection{Criação dos Itens}

Para a criação dos itens do Inventário de Barreiras e Facilitadores ao Empreendedorismo foi realizada uma revisão de literatura sobre as principais perspectivas teóricas e as mais recentes descobertas nesse âmbito, em que se buscou estabelecer os elementos que configuram Barreiras e Facilitadores ao Empreendedorismo e operacionalizar esses elementos em comportamentos observáveis e, consequentemente, em itens.

Para o desenvolvimento e escrita dos itens, foram considerados os 10 critérios recomendados por Pasquali (2010): (1) Critério comportamental; (2) Critério de objetividade ou de desejabilidade; (3) Critério da simplicidade; (4) Critério da clareza; (5) Critério da relevância; (6) Critério da precisão; (7) Critério da variedade; (8) Critério da modalidade; (9) Critério da tipicidade; e (10) Critério da credibilidade.

Assim, conforme a base teórica levantada, foram construídos 130 itens inseridos em 8 constructos independentes: 12 itens para Intenção de Empreender; 18 itens para Risco; 13 itens para Acesso à Capital; 16 itens para Inovação; 17 itens para Oportunidade; 22 itens para Liderança e Gerenciamento; 15 itens para Rede de Relacionamento; e 17 itens para Paixão

\subsection{Validade de Conteúdo}

A Validade de Conteúdo foi procedida por meio da análise de 7 (sete) juízes, sendo 3 especialistas em psicometria, 2 professores de Administração e 2 especialistas em Empreendedorismo. As definições constitutivas dos 8 constructos foram apresentadas aos juízes, que foram requeridos a indicar a associação entre o item e o respectivo construto que o representa, como adequado ou inadequado, e se a representação comportamental do item se referia ao traço latente proposto, considerando os critérios estabelecidos por Pasquali (2010).

A decisão sobre a escolha e permanência dos itens foi dada na concordância de no mínimo 80\% entre os juízes (PASQUALI, 2010), o que significou uma concordância entre 
pelo menos 5 dos 7 juízes participantes da análise de conteúdo. Como resultado, 24 itens foram pontuados como 'inadequado', restando 106 itens para as análises seguintes.

\subsection{Validade Semântica}

A Validade Semântica foi procedida por meio de uma análise semântica dos itens, em que se buscou verificar a inteligibilidade dos itens, verificando se eles foram construídos expressando o comportamento de forma clara e sem deixar dúvidas de interpretação e, também, se os itens não ficaram de forma deselegante (PASQUALI, 2010). Para esta etapa, contou-se com a participação de 2 pessoas de escolaridade até o Ensino Médio, 3 estudantes universitários de Administração e 4 professores de Administração. Todos os itens apresentados foram endossados pelos 9 participantes do processo de análise semântica.

\subsection{Procedimentos, Amostra e Coleta dos dados}

Contando com 106 itens da versão experimental do Inventário de Barreiras e Facilitadores ao Empreendedorismo, foi realizado um teste empírico visando a adequação aos parâmetros psicométricos de validade fatorial e consistência interna do instrumento proposto. Uma vez que se buscou uma medida de identificação de perfil empreendedor, o instrumento foi operacionalizado para validação considerando a diferenciação da população geral (estudantes universitários) frente ao público de empreendedores (empresários).

Participaram do estudo 251 pessoas, dos quais 57 empresários (52,6\% do sexo masculino) e 194 estudantes universitários diferentes (57,7\% do sexo feminino), com média de 30 anos (amplitude de 17 a 66 anos de idade; DP =10,4). Os participantes foram oriundos de 17 Estados Federativos do Brasil, sendo os Estados com maior incidência: Alagoas (58,6\%), São Paulo (12,7\%), Paraíba (9,6\%) e Rio Grande do Sul (8,4\%).

A aplicação da versão experimental do Inventário de Barreiras e Facilitadores ao Empreendedorismo (com 106 itens embaralhados) foi dada por acessibilidade, com amostragem de conveniência não-probabilística, junto a Estudantes Universitários e Empresários, os quais foram solicitados, de forma individual ou on-line via Google Docs, a responderem ao questionário, no período entre Fevereiro e Março de 2014. Os itens foram respondidos em uma escala tipo Likert de 5 (cinco) pontos, variando de $\mathbf{1}=$ Não me descreve em absoluto a $\mathbf{5}=$ Descreve-me totalmente.

Foi garantido o caráter voluntário da participação, o anonimato e o sigilo das respostas, bem como, o respeito às diretrizes éticas que regem a pesquisa com seres humanos. Utilizou-se o método survey, com a estratificação considerada a $95 \%$ de grau de confiabilidade, com margem de erro amostral padrão de $\pm 5 \%$.

\subsection{Análise dos dados}

REAd | Porto Alegre - Edição 85 - N 3 - Setembro / Dezembro 2016 - p. 381 - 412 
Por meio do software Statistical Package for Social Sciences (IBM/SPSS 21), foi verificada a adequação dos dados e a fatoriabilidade da matriz de correlações dos itens das escalas, respectivamente, por meio do Kaiser-Meyer-Olkin (KMO) e do Teste de Esfericidade de Bartlett, para então serem submetidos à análise fatorial. Devido à grande quantidade de itens submetidos à análise empírica e à separação conceitual de cada constructo, os 8 constructos foram operacionalizados em subescalas independentes e foram procedidas análises fatoriais por parcela de itens (ver, DAMÁSIO, 2012).

Partindo-se da análise fatorial por parcela de itens, foram realizadas em sequência 3 análises de fatores comuns (uma de cada vez) em cada conjunto de itens [estabelecidos teoricamente no mesmo constructo], fixada em 1 fator, com matriz não-rotacionada, para determinar os itens a serem selecionados para a versão final do instrumento proposto, tendo como critério de corte a não saturação dos itens, em cada um dos seguintes valores de carga fatorial, respectivamente, $|0,3|,|0,4|$ e $|0,5|$. Tal procedimento visa a obtenção de significância prática dos itens selecionados, o que garante resultados mais arrojados, exigindo-se seguir recomendações de Hair et al. (2010) para um valor limite inferior de carga fatorial de $|0,5|$.

Em seguida, foi realizada a escolha dos itens por meio dos critérios da parcimônia e da qualidade de explicação do constructo pertencente. Assim, foram escolhidos os 5 itens de cada subescala com maiores cargas fatoriais. Por conseguinte, procedeu-se à análise fatorial (fixada em 1 fator, com matriz não-rotacionada) e ao Alfa de Cronbach, para determinar os parâmetros finais de validade fatorial e consistência interna. O Alfa de Cronbach verifica a congruência que cada item tem com o restante dos itens do mesmo teste (PASQUALI, 2010), sendo o valor de 0,600 o limite inferior de aceitabilidade (HAIR et al., 2010).

Por conseguinte, para comprovar a estrutura empírica de cada uma das subescalas que compõem o Inventário de Barreiras e Facilitadores ao Empreendedorismo, foi realizada, em parcela de itens, a Análise Fatorial Confirmatória (AFC) por meio da Modelagem de Equações Estruturais. Para a realização da AFC, utilizou-se o software AMOS 7 (Analysis of Structures), considerando a matriz de covariâncias e adotando o método de estimação ML (Maximum Likelihood). Resumem-se, a seguir, os indicadores de qualidade de ajuste do modelo utilizados:

- O Qui-quadrado $\left(\chi^{2}\right)$ comprova a probabilidade do modelo se ajustar aos dados e assume a multinormalidade do conjunto de variáveis. Um valor do $\chi^{2}$ estatisticamente significativo indica discrepâncias entre os dados e o modelo teórico testado.

- O Índice de Qualidade do Ajuste (Goodness-of-Fit Index, GFI) e o Índice de Qualidade do Ajuste Ponderado (Adjusted Goodness-of-Fit Index, AGFI) levam em 
conta os graus de liberdade do modelo com respeito ao número de variáveis consideradas. São recomendados valores do GFI e AGFI superiores ou próximos a 0,95 e 0,90, respectivamente (ver, HU; BENTLER, 1999).

- O Índice de Ajuste Comparativo (Comparative Fit Index, CFI) é um índice comparativo, adicional, de ajuste ao modelo, com valores mais próximos de 1, indicando melhor ajuste, com 0,90 sendo a referência para aceitar o modelo.

- Razão $\chi^{2} / \mathrm{gl}$ é considerada uma qualidade de ajuste subjetiva (BYRNE, 2001). Um valor entre 1,00 e 2,00 pode ser interpretado como indicador de adequação do modelo teórico para descrever os dados.

- A Raiz Quadrada Média Residual (Root Mean Square Residual, RMR) baseia-se nos residuais, sendo que um valor próximo a zero significa que o modelo se ajusta aos dados, indicando que todos os residuais se apresentam mais perto deste valor. Considerar-se-á a $R M R$ padronizada; um valor em torno de 0,05 é considerado uma prova da adequação do modelo (SARIS; STRONKHORST, 1984).

- Para a Raiz Quadrada Média do Erro de Aproximação (Root Mean Square Error of Approximation, RMSEA), recomendam-se valores iguais ou abaixo de 0,08 (HU; BENTLER, 1999), com intervalo de confiança de 90\% (IC90\%).

Para explicar a estrutura dimensional do Inventário de Barreiras e Facilitadores ao Empreendedorismo procedeu-se ao Escalonamento Multidimensional (MDS) [ALSCAL], utilizando-se o software estatístico IBM/SPSS (versão 21), considerando a criação de matriz de distância bidimensional para todos os constructos (somatórios dos itens de cada subescala) em um modelo de distância euclidiana. Em complemento, utilizou-se a Correlação $r$ de Pearson para dar suporte à explicação da estrutura dimensional.

Por fim, foi realizada a validade de critério para aferir a eficácia preditiva do instrumento (PASQUALI, 2010) em identificar o comportamento de empreendedores. Para a validade de critério foi procedido o teste $t$ de Student, para amostras independentes, e o Tamanho do Efeito $(d)$, seguindo-se as recomendações de Cohen (1992), em que, $d=0,20$ denota um efeito pequeno, $d=0,50$ denota um efeito médio e $d=0,80$ denota um efeito grande. Segundo Dancey e Reidy (2013), quando se avalia constructos comportamentais e psicossociais entre diferentes grupos - devido à interferência de elementos subjetivos e contextuais -, efeitos pequenos e medianos são mais facilmente encontrados, como é o caso dos constructos aqui apresentados. Neste caso, os valores medianos denotam um test $t$ satisfatório, enquanto os valores pequenos (acima de 0,3) denotam um test $t$ apenas aceitável. 
O teste $t$ foi aplicado na comparação dos escores médios de estudantes universitários e empresários para cada uma das subescalas, visando identificar se o instrumento era capaz de predizer o comportamento do empreendedor - estatisticamente significativo a um nível de probabilidade associada de $\mathrm{p}<0,05$-, uma vez que, se parte do pressuposto que, o empresário tende a ser mais empreendedor que a população geral.

\section{RESULTADOS}

\subsection{Análises iniciais: Fatoriabilidade, Redução e Escolha dos Itens}

Procedeu-se à análise das estatísticas iniciais de fatoriabilidade da matriz de correlação e da adequação da amostragem à análise fatorial. As estatísticas de Kaiser-Meyer-Olkin $(K M O)=0,900$ e do Teste de Esfericidade de Bartlett, $\chi^{2}(5565)=18461,569 ; p=0,000$, evidenciaram adequação 'admirável' da amostra ao instrumento e fatoriabilidade 'satisfatória', de acordo com a concepção de Hair et al. (2010).

Aferida a adequação dos dados, estes foram submetidos à análise fatorial por parcela de itens - itens de cada subescala separadamente -, fixada em 1 fator, com matriz nãorotacionada. Visando a redução de itens em cada subescala, realizou-se a análise fatorial exploratória levando em consideração como ponto de corte inicial os itens abaixo do valor de carga fatorial $|0,3|$, em seguida, após a realização de uma nova análise fatorial por parcela de itens, considerou-se como ponte de corte valores abaixo de carga fatorial |0,4|, e por fim, após a realização de mais uma análise fatorial por parcela de itens, considerou-se como ponte de corte valores abaixo de carga fatorial $|0,5|$. Esta etapa registrou a não saturação dos seguintes itens para cada umas das subescalas (Tabela 1):

Tabela 1: Itens reduzidos nas análises iniciais

\begin{tabular}{|c|c|c|c|c|c|c|}
\hline \multirow{2}{*}{ Subescala } & \multicolumn{2}{|c|}{ Valores abaixo de $|0,3|$} & \multicolumn{2}{|c|}{ Valores abaixo de $|0,4|$} & \multicolumn{2}{|c|}{ Valores abaixo de $\mid 0,5$} \\
\hline & Analisados & Excluídos & Analisados & Excluídos & Analisados & Excluídos \\
\hline Intenção de Empreender & 9 itens & - & 9 itens & - & 9 itens & - \\
\hline Risco & 16 itens & 2 Itens & 14 itens & 3 Itens & 11 itens & - \\
\hline Acesso à Capital & 10 itens & 1 Item & 9 itens & 1 Item & 8 itens & 2 Itens \\
\hline Inovação & 15 itens & 1 Item & 14 itens & 1 Item & 13 itens & 2 Itens \\
\hline Oportunidade & 16 itens & - & 16 itens & 2 Itens & 14 itens & - \\
\hline $\begin{array}{l}\text { Liderança e } \\
\text { Gerenciamento }\end{array}$ & 17 itens & 1 Item & 16 itens & - & 16 itens & 5 Itens \\
\hline Rede de Relacionamento & 11 itens & 1 Item & 10 itens & - & 10 itens & 1 Item \\
\hline Paixão & 12 itens & 1 Item & 11 itens & - & 11 itens & 1 Item \\
\hline Totais & 106 itens & 7 Itens & 99 & 7 Itens & 92 & 11 Itens \\
\hline
\end{tabular}

Fonte: Dados da pesquisa.

Após as 3 análises fatoriais por parcela de itens, obteve-se uma redução total de 25 itens não saturados, apresentando 81 itens com evidências de validade fatorial. Assim, para a escolha dos itens, buscou-se arbitrariamente utilizar 2 critérios: (1) critério da parcimônia, isto é, obter uma medida prática, satisfatória e econômica; e, (2) critério da qualidade de 
explicação, isto é, escolher apenas os melhores itens de cada subescala - especificamente, os com maiores cargas fatoriais. Nesse sentido, ajuizou-se que os 5 itens de cada subescala, com maior carga fatorial, seriam escolhidos para compor a versão final de 40 itens do Inventário de Barreiras e Facilitadores ao Empreendedorismo.

\subsection{Validade Fatorial e Consistência Interna da Versão de 40 itens do Inventário de}

\section{Barreiras e Facilitadores ao Empreendedorismo: Parâmetros Finais}

Contando com a versão de 40 itens do Inventário de Barreiras e Facilitadores ao Empreendedorismo (Apêndice A), foram procedidas análises fatoriais por parcela de itens (componentes principais, com matriz não-rotacionada) e o teste do Alfa de Cronbach, considerando os 5 itens escolhidos de cada uma das subescalas, para determinar os parâmetros finais de validade fatorial e consistência interna.

Tabela 2: Resumo das Cargas fatoriais, Alfas e Variâncias explicadas das Subescalas

\begin{tabular}{lcccc}
\hline Subescalas & Itens & $\begin{array}{c}\text { Cargas } \\
\text { Fatoriais* }\end{array}$ & $\begin{array}{c}\text { Alfa de } \\
\text { Cronbach }\end{array}$ & Variância Explicada \\
\hline Intenção de Empreender & 5 & $0,744-0,898$ & 0,893 & $70,154 \%$ \\
\hline Risco & 5 & $0,768-0,826$ & 0,860 & $64,324 \%$ \\
\hline Acesso à Capital & 5 & $0,741-0,803$ & 0,813 & $57,439 \%$ \\
\hline Inovação & 5 & $0,705-0,854$ & 0,840 & $61,141 \%$ \\
\hline Oportunidade & 5 & $0,806-0,863$ & 0,883 & $68,707 \%$ \\
\hline Liderança e Gerenciamento & 5 & $0,737-0,842$ & 0,847 & $62,434 \%$ \\
\hline Rede de Relacionamento & 5 & $0,640-0,835$ & 0,783 & $54,030 \%$ \\
\hline Paixão & 5 & $0,715-0,831$ & 0,838 & $60,918 \%$ \\
\hline
\end{tabular}

Fonte: Dados da pesquisa. Notas. * Considerou-se o intervalo mínimo e máximo.

Verifica-se, na Tabela 2, que todas as subescalas apresentaram validade fatorial e consistência interna a níveis de significância prática, de forma que o constructo que representa cada subescala pode ser interpretado a partir de seus 5 itens.

\subsection{Validação Confirmatória e Dimensionalidade}

Visando comprovar a estrutura empírica do instrumento proposto, os itens de cada subescala foram submetidos, separadamente, à modelagem por equações estruturais, hipotetizando um fator latente de primeira ordem para cada constructo que explicaria seus respectivos itens. Assim, procedeu-se a validade fatorial confirmatória, considerando a matriz de covariâncias e adotando o método de estimação ML (Maximum Likelihood). As análises iniciais indicaram a necessidade de reespecificação do modelo de 7 constructos, que exigiram pelo menos um par de itens a terem seus índices de modificação correlacionados. Após o ajuste, os modelos obtiveram bons indicadores de adequação (Tabela 3 ).

Tabela 3: Índices de adequação dos modelos testados para cada uma das subescalas

\begin{tabular}{ccccccccccc}
\hline Subescala & $\chi^{2}$ & gl & $\boldsymbol{p}$ & $\chi^{2} / \mathbf{g l}$ & $\mathbf{R M R}$ & GFI & AGFI & CFI & $\begin{array}{c}\text { RMSEA } \\
(\mathbf{9 0} \% \text { CI })\end{array}$ & CAIC \\
\hline $\begin{array}{c}\text { Intenção de } \\
\text { Empreender }\end{array}$ & 6,102 & 4 & 0,192 & 1,526 & 0,020 & 0,990 & 0,964 & 0,997 & $\begin{array}{c}0,046 \\
(0,00-0,11)\end{array}$ & 77,88 \\
\hline
\end{tabular}




\begin{tabular}{ccccccccccc}
\hline Risco $^{2}$ & 5,445 & 4 & 0,245 & 1,361 & 0,027 & 0,991 & 0,968 & 0,997 & $\begin{array}{c}0,038 \\
(0,00-0,10)\end{array}$ & 77,22 \\
\hline Acesso à Capital $^{3}$ & 10,00 & 4 & 0,04 & 2,502 & 0,036 & 0,984 & 0,941 & 0,984 & $\begin{array}{c}0,078 \\
(0,01-0,13)\end{array}$ & 81,78 \\
\hline Inovação $^{4}$ & 4,965 & 3 & 0,174 & 1,655 & 0,018 & 0,992 & 0,961 & 0,996 & $\begin{array}{c}0,051 \\
(0,00-0,12)\end{array}$ & 83,27 \\
\hline Oportunidade $^{5}$ & 1,092 & 1 & 0,296 & 1,092 & 0,009 & 0,998 & 0,974 & 0,999 & $\begin{array}{c}0,019 \\
(0,00-0,17)\end{array}$ & 92,44 \\
\hline $\begin{array}{c}\text { Liderança e } \\
\text { Gerenciamento }^{6}\end{array}$ & 8,992 & 4 & 0,061 & 2,248 & 0,025 & 0,986 & 0,946 & 0,990 & $\begin{array}{c}0,071 \\
(0,00-0,13)\end{array}$ & 80,77 \\
\hline Rede $^{7}$ & 10,14 & 5 & 0,071 & 2,029 & 0,049 & 0,985 & 0,954 & 0,984 & $\begin{array}{c}0,064 \\
(0,00-0,12)\end{array}$ & 75,40 \\
\hline Paixão & 1,380 & 1 & 0,240 & 1,380 & 0,006 & 0,998 & 0,967 & 0,999 & $\begin{array}{c}0,039 \\
(0,00-0,17)\end{array}$ & 92,73 \\
\hline
\end{tabular}

Fonte: Dados da pesquisa. Notas. ${ }^{1}$ Uma interação com covariância; ${ }^{2}$ Uma interação com covariância; ${ }^{3}$ Uma interação com covariância; ${ }^{4}$ Duas interações com covariância ${ }^{5}$ Quatro interações com covariância; ${ }^{6}$ Uma interação com covariância; ${ }^{7}$ Nenhuma interação com covariância; ${ }^{8}$ Quatro interações com covariância.

Ademais, ressalta-se que as correlações indicadas pelos índices de modificação apontam para uma redundância dos itens, demonstrando que as subescalas avaliam proficuamente o constructo, mesmo se suprimido um dos itens correlacionados, visto que são pares redundantes no fator latente que mensuram.

Ao analisar a estrutura dimensional do Inventário de Barreiras e Facilitadores ao Empreendedorismo através do $M D S[R S Q=0,97$ e $S$-stress $=0,066]$ (Figura 1), verifica-se pelo menos 4 dimensões evidentes. A primeira é a dimensão formada pelas subescalas Paixão (P), Inovação (I), e Liderança e Gerenciamento (LG), que apresentam fortes correlações [P-I: $r=0,509 ; p=0,000$; I-LG: $r=0,465 ; p=0,000$; P-LG: $r=0,574 ; p=0,000]$. A segunda dimensão é formada pelas subescalas Rede de Relacionamentos e Acesso à Capital (dimensão social) $[r=0,732 ; p=0,000]$. A terceira dimensão é formada pelas subescalas Oportunidade e Risco (dimensão contextual) $[r=0,738 ; p=0,000]$. E a quarta dimensão formada unicamente pela subescala Intenção de Empreender.

Figura 1 - Dimensionalidade do Inventário de Barreiras e Facilitadores ao Empreendedorismo

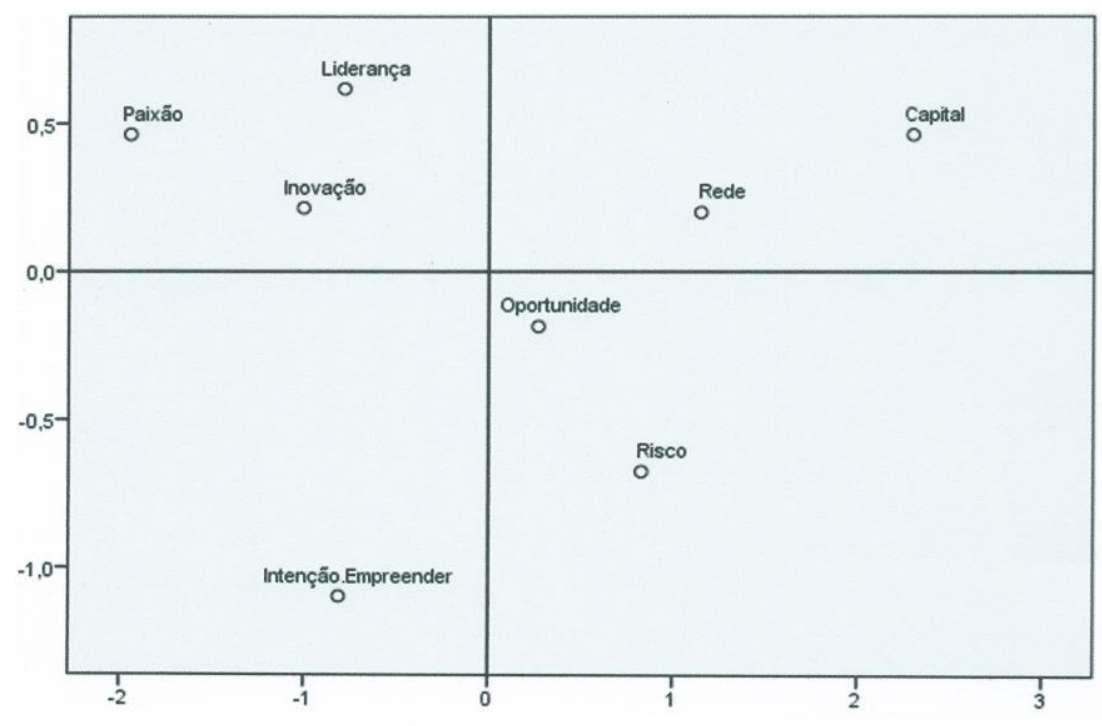

Fonte: Autores. 
As subescalas se agrupam em dimensões separadas, por exemplo, Rede de Relacionamentos e Acesso à Capital, devido a uma covariância que pode ser explicada de duas formas. A primera é a proximidade semântica que alguns itens dessas subescalas possuem, por exemplo, os itens V3b - Conheço pessoas que poderiam me ajudar com dinheiro para eu abrir meu negócio (Acesso à Capital) e V7b - Possuo uma rede de contatos que poderia me auxiliar na abertura de um negócio (Rede de Relacionamentos) [correlação entre os itens: $r=0,429 ; p=0,000]$. A segunda é que ambos são constructos sociais que representam duas situações distintas: (1) 'dinheiro', que distingue os níveis sociais e (2) 'sociabilidade', que distingue a habilidade de relacionamento.

Quanto à Intenção de Empreender, o MDS aponta esta subescala como parte de uma dimensão separada das demais subescalas. Autores de outros instrumentos relacionados ao comportamento empreendedor têm tratado a Intenção de Empreender como elemento complementar (e.g., KRISTIANSEN; INDARTI, 2004; SANTOS, 2008) ou de baixa influência (e.g., LOPES JUNIOR; SOUZA, 2005; GONÇALVES FILHO; CEIT; GONÇALVES, 2007) ao perfil empreendedor. Isso porque, têm sido encontrados resultados que indicam que a Intenção de Empreender é um elemento multifacetado. A exemplo disso, autores como Dolabela et al. (2008) e Santos, Dantas e Milito (2010) reportam relações claras entre o desejo de ter um negócio e fatores como cultura familiar e dinâmica econômica local, o que tornaria a intenção de empreender um vetor cultural no comportamento empreendedor.

Aqui, toma-se a Intenção de Empreender como elemento relacionado ao desejável e, portanto, uma Barreira ou Facilitador para a ação de empreender, uma vez que a não intenção de empreender é um critério de inibição [Barreira], enquanto que a intenção de empreender é um catalisador em condições de alta favorabilidade [Facilitador], como fácil acesso à capital.

\subsection{Validade de Critério}

Tendo-se os parâmetros finais de validade fatorial e consistência interna do Inventário de Barreiras e Facilitadores ao Empreendedorismo, procedeu-se então à validade de critério, buscando aferir a eficácia preditiva do instrumento. Por meio do teste $t$ de Student, verificouse a existência de diferença significativa entre os escores médios de estudantes universitários e empresários para cada uma das subescalas, em função do critério de que o empresário possui um comportamento mais empreendedor do que a população geral.

Na Tabela 4, estão dispostos os parâmetros da validade de critério, em que estão apresentados: as médias e desvios padrão (DP), o valor do teste $t$, os graus de liberdade (gl), o valor $p$ de significância, a diferença das médias associada a um intervalo de confiança de $95 \%$ e os valores $d$ para o Tamanho do Efeito do teste $t$. 
Tabela 4: Parâmetros da Validade de Critério

\begin{tabular}{|c|c|c|c|c|c|c|c|c|c|}
\hline \multirow[t]{2}{*}{ Subescalas } & \multicolumn{2}{|c|}{$\begin{array}{c}\text { Estudantes } \\
\text { Universitários } \\
(n=194)\end{array}$} & \multicolumn{2}{|c|}{$\begin{array}{l}\text { Empresários } \\
\qquad(\mathbf{n}=\mathbf{5 7})\end{array}$} & \multicolumn{5}{|c|}{ Estatísticas } \\
\hline & Média & DP & Média & DP & $t$ & gl & $p$ & $\begin{array}{l}\text { Diferença } \\
\text { das Médias } \\
\text { (IC95\%) }\end{array}$ & $d$ \\
\hline $\begin{array}{l}\text { Intenção de } \\
\text { Empreender }\end{array}$ & 3,91 & 1,068 & 4,27 & 0,792 & $-2,806$ & 121,69 & 0,006 & $\begin{array}{c}0,37 \\
(0,09-0,64)\end{array}$ & 0,39 \\
\hline Risco & 3,14 & 1,010 & 3,65 & 0,887 & $-3,425$ & 249 & 0,001 & $\begin{array}{c}0,51 \\
(0,22-0,80)\end{array}$ & 0,52 \\
\hline $\begin{array}{c}\text { Acesso à } \\
\text { Capital }\end{array}$ & 2,65 & 0,913 & 3,05 & 0,916 & $-2,908$ & 249 & 0,004 & $\begin{array}{c}0,40 \\
(0,13-0,67) \\
\end{array}$ & 0,44 \\
\hline Inovação & 3,90 & 0,801 & 4,19 & 0,693 & $-2,427$ & 249 & 0,016 & $\begin{array}{c}0,29 \\
(0,05-0,52)\end{array}$ & 0,37 \\
\hline Oportunidade & 3,39 & 0,904 & 3,94 & 0,732 & $-4,667$ & 110,89 & 0,000 & $\begin{array}{c}0,54 \\
(0,29-0,80)\end{array}$ & 0,63 \\
\hline $\begin{array}{c}\text { Liderança e } \\
\text { Gerenciamento }\end{array}$ & 3,87 & 0,803 & 4,21 & 0,700 & $-2,904$ & 249 & 0,004 & $\begin{array}{c}0,34 \\
(0,11-0,57)\end{array}$ & 0,44 \\
\hline $\begin{array}{c}\text { Rede de } \\
\text { Relacionamento }\end{array}$ & 3,05 & 0,953 & 3,61 & 0,748 & $-4,036$ & 249 & 0,000 & $\begin{array}{c}0,56 \\
(0,29-0,82) \\
\end{array}$ & 0,61 \\
\hline Paixão & 4,34 & 0,635 & 4,62 & 0,533 & $-3,322$ & 107,04 & 0,001 & $\begin{array}{c}0,28 \\
(0,10-0,46)\end{array}$ & 0,46 \\
\hline
\end{tabular}

Fonte: Dados da pesquisa.

Conforme se verifica na Tabela 4, em todas as subescalas os empresários pontuaram mais alto que os estudantes universitários e essa diferença foi estatisticamente significativa a um valor de $p \leq 0,05$, mostrando um Tamanho do Efeito $(d)$ mediado, exceto para as subescalas Intenção de Empreender e Inovação. Os efeitos medianos mostram que a diferença entre empreendedores e estudantes universitários foi relevante, enquanto que os efeitos pequenos denotam apenas a existência de diferença, embora seja uma diferença de fato fraca.

Ressalta-se que a validade de critério demonstrou que o instrumento consegue diferenciar de modo fidedigno o empreendedor da população geral. $\mathrm{O}$ teste $t$ revelou que a principal diferença entre empreendedores e estudantes universitários (população geral) está nos constructos Oportunidade e Rede de Relacionamento, isto é, os empreendedores possuem senso de oportunidade (identificação, valoração e exploração) mais elevado que os estudantes universitários e melhores redes de relacionamento para a obtenção de recursos e capital.

Quanto aos baixos valores para o Tamanho do Efeito das subescalas Intenção de Empreender $(d=0,39)$ e Inovação $(d=0,37)$, Santos (2008) encontrou resultados que mostram que o desejo ou vontade de ter o próprio negócio e de ser uma pessoa inovadora não são particulares a empreendedores. Gouveia et al. (2009), explicam que, comumente, em instrumentos do tipo autorrelato existem questões que sofrem influência de normas sociais e padrões relativos ao desejável, o que dissimula a resposta real do indivíduo. Assim, a Intenção de Empreender e a Inovação, ambas encontradas em empreendedores e em nãoempreendedores, podem ser explicadas pela desejabilidade social. Por exemplo, o indivíduo 
não-empreendedor pode ter sido levado a crer que abrir um negócio (ser empresário) o faria ser reconhecido, ficar rico e inserir-se em meios sociais, impelindo-o a pensar que desejar empreender é algo bom, quando, na verdade, ele não tem a real intenção de abrir um negócio.

\section{CONSIDERAÇÕES FINAIS}

O objetivo deste estudo foi construir e validar o Inventário de Barreiras e Facilitadores ao Empreendedorismo. Os resultados indicam uma boa adequação da estrutura empírica do instrumento proposto, formando uma medida multidimensional e funcionalista, composta por 8 subescalas independentes (Intenção de Empreender; Risco; Acesso à Capital; Inovação; Oportunidade; Liderança e Gerenciamento; Rede de Relacionamento; Paixão) que convergem para a predição do comportamento empreendedor a partir de fatores que favorecem e inibem esta ação. O instrumento apresenta parâmetros psicométricos que indicam sua validade, confiabilidade e precisão.

O propósito deste trabalho foi superar, se não todas, algumas das limitações encontradas nos instrumentos anteriomente construídos. Buscou-se construir um instrumento de amplo alcance e seguindo as recomendações de Sarasvathy (2004), que propõe a valoração das Barreiras ao empreendedorismo (elementos socias e contextuais) como o melhor modelo para identificação de perfis empreendedores. Assim, este instrumento leva em consideração um empreendedor universal, não sustentado por características de uma determinada cultura, como os instrumentos de Kristiansen e Indarti (2004) ou de Santos (2008).

Além disso, Cardon et al. (2013) afirmam que os instrumentos de identificação do comportamento empreendedor, até então desenvolvidos, negligenciam dimensões afetivas, especificamente, a Paixão. Desse modo, optou-se por criar um instrumento que abarcasse dimensões afetivas, psicossociais e contextuais. O que nos levou a incluir o fator Paixão.

Também, os resultados mostram que o comportamento empreendedor associado a Barreiras e Facilitadores é explicado por blocos de constructos que perfazem 4 dimensões:

(1) A dimensão comportamental/afetiva diz respeito a fatores que existem a partir de traços disposicionais individuais e aspectos cognitivos, sugerindo uma relação com o estilo comportamental/afetivo que o indivíduo possui (MINER, 2000; LIMA; FREITAS, 2010; BRANDSTÄTTER, 2011), o que abarca os constructos Paixão, Inovação e Liderança.

(2) A dimensão social se caracteriza por abarcar os constructos Acesso à Capital e Rede de Relacionamento, representando duas situações distintas. A primeira situação diz respeito ao capital (dinheiro), que distingue os níveis sociais - ter capital ou acesso facilitado ao capital é uma condição social (BRUSH; GREENE; HART, 2002; KRISTIANSEN; INDARTI, 2004). A segunda situação diz respeito às relações interpessoais e parcerias, que 
distingue a habilidade de relacionamento possuída pelo empreendedor, isto é, sua capacidade/habilidade de sociabilidade (SHENG, 2008; NASSIF; GHOBRIL; SILVA, 2010).

(3) A dimensão contextual abarca os constructos Oportunidade e Risco, os quais representam um contexto externo ao indivíduo, ou seja, elementos socioeconomicos (crescimento do PIB), políticos (promulgação de leis ou isenção de impostos) e ambientais (mudanças climáticas), não controlados e que podem influir, por exemplo, na existência de oportunidades de negócio ou se instituir como um risco para negócios já existentes (SARASON; DEAN; DILLARD, 2006; SANTOS-ÁLVAREZ; GARCÍA-MERINO, 2010).

(4) A dimensão de intenção se caracteriza apenas pelo constructo Intenção de Empreender. A intenção de empreender é uma predisposição do indivíduo aos negócios que é subsidiada por elementos, como: gênero, idade, nível educacional, experiências de trabalho, necessidade de realização, lócus de controle, acesso à capital, acesso à informação e redes sociais (KRISTIANSEN; INDARTI, 2004).

Notadamente, chegou-se a um instrumento de baixo custo (lápis e papel) e de fácil aplicação (autorrelato) que apresenta parâmetros de validade de conteúdo e semântica, validade fatorial e consistência interna e validade de critério. O instrumento é capaz de identificar o comportamento empreendedor por meio de fatores individuais, psicossociais e contextuais, de modo que molda um indivíduo empreendedor, podendo ser empregado em estudos que visem conhecer os antecedentes e consequentes desse comportamento.

A aplicabilidade do Inventário de Barreiras e Facilitadores ao Empreendedorismo está em seu universalismo e adaptabilidade, visto que o instrumento é formado por facetas subescalas independentes - que podem ser mensuradas separadamente a depender da necessidade do pesquisador. Assim, é possível fazer uso do instrumento em diferentes contextos, como concessão de empréstimos para a abertura de negócios (e.g., BNDES), treinamentos, processos seletivos, identificação de perfil empreendedor entre empregados (intraempreendedorismo), incentivo à carreira empresarial a partir de aptidões previamente identificadas e estudos entre profissões que, comumente, tendem a levar o indivíduo à abertura de negócios, como médicos, contadores, engenheiros, dentre outros.

Apesar disso, existem limitações que se recaem sobre a amostra. Basicamente, utilizase a mesma amostra para todos os procedimentos de validação, quando o mais recomendável seria a replicação do instrumento em uma nova amostra para a verificação da validade fatorial confirmatória (ver, DAMÁSIO, 2012).

Para a agenda de estudos futuros, pontua-se a necessidade de replicação do Inventário de Barreiras e Facilitadores ao Empreendedorismo em outras amostras, para que sejam REAd | Porto Alegre - Edição 85 - N 3 - Setembro / Dezembro 2016 - p. 381 - 412 
aferidos novos parâmetros de validação confirmatória. Também, reporta-se a necessidade de revalidação do Inventário de Barreiras e Facilitadores ao Empreendedorismo para outros contextos e outras línguas, para que sejam aferidos parâmetros de validade mais amplos, incentivando a difusão de seu uso. Por fim, para que se tenha um balizador de interpretação do Inventário de Barreiras e Facilitadores ao Empreendedorismo, visando estudos futuros, recomenda-se arbitrariamente como critério para a atribuição dos Facilitadores em sobrepujo às Barreiras, a pontuação dentro da amplitude da média dos empresários em cada subescala.

\section{REFERÊNCIAS}

ABEBE, M. A. Social and institutional predictors of entrepreneurial career intention: evidence from Hispanic adults in the U.S. Journal of Enterprising Culture, Toronto, v. 20, n. 1, p. 1-23, 2012.

AKHTAR, C. S. et al. Investigating the moderating effect of family on the relationship between entrepreneurial orientation and success of enterprise: case of Pakistani manufacturing SMEs. International Journal of Entrepreneurship and Small Business, v. 26, n. 2, p. 233 247, 2015.

ALDRICH, H.; ROSEN, B.; WOODWARD, W. The impact of social networks on business foundings and profit: a longitudinal study. In: Frontiers of Entrepreneurship Research. Wellesley, MA: Babson College, 1987. pp. 154-168.

ALENCAR, E. M. L. S. Inventário de barreiras à criatividade pessoal. In: ALENCAR, E. M. L. S.; BRUNO-FARIA, M. de F.; FLEITH, D. de S. (Orgs.). Medidas de criatividade. Porto Alegre: Artmed, 2010. p. 35-54.

ALVES, L. R. R.; BORNIA, A. C. Desenvolvimento de uma escala para medir o potencial empreendedor utilizando a Teoria da Resposta ao Item (TRI). Gestão \& Produção, São Carlos, v. 18, n. 4, p. 775-790, 2011.

ANGGADWITA, G.; DHEWANTO, W. The influence of personal attitude and social perception on women entrepreneurial intentions in micro and small enterprises in Indonesia. International Journal of Entrepreneurship and Small Business, v. 27, n. 2/3, p. 131-148, 2016.

BARBA-SÁNCHEZ, V.; ATIENZA-SAHUQUILLO, C. Entrepreneurial behavior: Impact of motivation factors on decision to create a new venture. Investigaciones Europeas de Dirección y Economía de la Empresa, Vigo, v. 18, n. 2, p. 132-138, 2012. 
BARLACH, L. Empreendedorismo ou profissão: um desafio para orientadores(as). Revista Brasileira de Orientação Profissional, São Paulo, v. 12, n. 1, p. 119-125, 2011.

BYRNE, B. M. Structural equation modeling with Amos: Basic concepts, applications, and programming. Mahwah, NJ: Lawrence Erlbaum Associates, 2001.

BRANDSTÄTTER, H. Personality aspects of entrepreneurship: A look at five meta-analyses. Personality and Individual Differences, London, v. 51, n. 3, p. 222-230, 2011.

BRUSH, C.; GREENE, P.; HART, M. Empreendedorismo e construção da base de recursos. Revista de Administração de Empresas, Rio de Janeiro, v. 42, n. 1, p. 20-35, 2002.

BYGRAVE, W. D. The entrepreneurial process. In: BYGRAVE, W. D.; ZACHARAKIS, A. (Eds.). The portable MBA in entrepreneurship. Hoboken, NJ: John Wiley \& Sons, 2004.

CANTILLON, R. Essai sur la nature du commerce en général. Londres: Chez Fletcher Gylesdans Holborn, 1755.

CARDON, M. S. Is passion contagious? The transference of entrepreneurial passion to employees. Human Resource Management Review, Athens, v. 18, n. 2, p. 77-86, 2008.

CARDON, M. S. et al. Measuring entrepreneurial passion: Conceptual foundations and scale validation. Journal of Business Venturing, Indiana, v. 28, n. 3, p. 373-396, 2013.

CARDON, M. S.; KIRK, C. P. Entrepreneurial passion as mediator of the self-efficacy to persistence relationship. Entrepreneurship Theory and Practice, v. 39, n. 5, p. 1027-1050, 2015 .

CARLAND, J. W.; CARLAND, J. A.; HOY, F. S. An entrepreneurship index: an empirical validation. Frontiers of Entrepreneurship Research, Babson Park, v. 25, n. 3, p. 244-265, 1992.

CARLAND, J. W.; CARLAND, J. A.; HOY, F. S. Who is an entrepreneur? Is a question worth asking? American Journal of Small Business, Malden, v. 15, n. 3, p. 33-39, 1998.

CASSAR, G. Entrepreneur opportunity costs and intended venture growth. Journal of Business Venturing, Indiana, v. 21, n. 5, p. 610-632, 2006. 
CASSON, M. The individual - opportunity nexus: a review of Scott Shane: a general theory of entrepreneurship. Small Business Economics, New York, v. 24, p. 423-430, 2005.

CHANDLER, G. N. Control structures used in family business to manage wealth: operationalization of antecedent and outcome variables. Entrepreneurship Theory and Practice, v. 39, n. 6, p. 1305-1312, 2015.

CHOI, Y. R.; LÉVESQUE, M.; SHEPHERD D. A. When should entrepreneurs expedite or delay opportunity exploitation? Journal of Business Venturing, Indiana, v. 23, n. 3, p. 333$355,2008$.

COHEN, J. A power primer. Psychological Bulletin, Washington, v. 112, n. 1, p. 155-159, 1992.

CORBETT, A. C. Experiential learning within the process of opportunity identification and exploitation. Entrepreneurship Theory and Practice, Malden, v. 29, n. 4, p. 473-491, 2005.

CROUSE, P.; DOYLE, W.; YOUNG, J. D. Workplace learning strategies, barriers, facilitators and outcomes: a qualitative study among human resource management practitioners. Human Resource Development International, Minnesota, v. 14, n. 1, p. 39$55,2011$.

DAMÁSIO, B. F. O uso da análise fatorial exploratória em psicologia. Avaliação Psicológica, Itatiba, v. 11, n. 2, p. 213-228, 2012.

DANCEY, C. P.; REIDY, J. Estatística sem matemática para psicologia. 5. ed. Porto Alegre: Penso, 2013.

DORNELAS, J. C. A. Empreendedorismo corporativo: conceitos e aplicações. Revista de Negócios, Blumenau, v. 9, n. 2, p. 81-90, 2004.

DRUCKER, P. F. Innovation and entrepreneurship. New York: Harper Business, 1993.

FILION, L. J. Operators and visionaries: differences in the entrepreneurial and managerial systems of two types of entrepreneurs. International Journal of Entrepreneurship and Small Business, Massachusetts, v. 1, n. 1-2, p. 35-55, 2004. 
FOO, M.; UY, M. A.; MURNIEKS, C. Beyond affective valence: Untangling valence and activation influences on opportunity identification. Entrepreneurship Theory and Practice, v. 39, n. 2, p. 407-431, 2015.

FRANKE, N.; LUTHJE, C. Entrepreneurial intentions of business students: a benchmarking study. International Journal of Innovation and Technology Management, Portland, v. 1, n. 3, p. 269-288, 2004.

GELDEREN, M. v. et al. Explaining entrepreneurial intentions by means of the theory of planned behavior. Career Development International, Illinois, v. 13, n. 6, p. 538-559, 2008.

GONÇALVES FILHO, C.; VEIT, M.; GONÇALVES, C. A. Mensuração do perfil do potencial empreendedor e seu impacto no desempenho das pequenas empresas. Revista de Negócios, Blumenau, v. 12, n. 3, p. 29-44, 2007.

GOUVEIA, V. V. et al. Escala de desejabilidade social de Marlowe-Crowne: evidências de sua validade fatorial e consistência interna. Avaliação Psicológica, Itatiba, v. 8, n. 1, p. 87-98, 2009.

GOUVEIA, V. V.; MILFONT, T. L.; GUERRA, V. M. Functional theory of human values: Testing its content and structure hypotheses. Personality and Individual Differences, London, v. 60, p. 41-47, 2014.

GUISO, L.; SCHIAVARDI, F. Learning to be an entrepreneur. Londres: Centre for Economic Policy Research, 2005.

HAIR Jr., J. F. et al. Multivariate data analysis. Upper Saddle River: Pearson, 2010.

HARMELING, S.; SARASVATHY, S. D.; FREEMAN, R. E. Related debates in ethics and entrepreneurship: values, opportunities and contingency. Journal of Business Ethics, Dordrecht, v. 84, n. 3, p. 441-365, 2009.

HISRICH, R. D.; PETERS, M. P.; SHEPHERD, D. Empreendedorismo. 9. ed. Porto Alegre: AMGH, 2014.

HU, L.; BENTLER, P. M. Cutoff criteria for fit indexes in covariance structure analysis: Conventional criteria versus new alternatives. Structural Equation Modeling, Santa Barbara, v. 6, p. 1-55, 1999. 
KANTIS, H. Overview: Main lessons for Latin America. In: KANTIS, H.; ANGELELLI, P.; KOENIG, V. M. (Eds.). Developing entrepreneurship: Experience in Latin America and worldwide. Washington: Inter-American Development Bank, 2005. pp. 207-214.

KARABEY, C. N. Understanding entrepreneurial cognition through thinking style, entrepreneurial alertness and risk preference: do entrepreneurs differ from others? Procedia Social and Behavioral Sciences, Victoria, v. 58, p. 861-870, 2012.

KAUTONEN, T.; GELDEREN, M.; FINK, M. Robustness of the theory of planned behavior in predicting entrepreneurial intentions and actions. Entrepreneurship Theory and Practice, v. 39, n. 3, p. 655-674, 2015.

KLINE, R. B. Principles and practice of structural equation modeling. New York: The Guilford Press, 2011.

KRISTIANSEN, S.; INDARTI, N. Entrepreneurial intention among Indonesian and Norwegian students. Journal of Enterprising Culture, Toronto, v. 12, n. 1, p. 55-78, 2004.

LAAKSONEN, L.; AINAMO, A.; KARJALAINEN, T. Entrepreneurial passion: an explorative case study of four metal music ventures. Journal of Research in Marketing and Entrepreneurship, Cardiff, v. 13, n. 1, p. 18-36, 2011.

LIMA, R. C. R.; FREITAS, A. A. F. Personalidade empreendedora, recursos pessoais, ambiente, atividades organizacionais, gênero e desempenho financeiro de empreendedores informais. Revista de Administração Pública, Rio de Janeiro, v. 44, n. 2, p. 511-531, 2010.

LOCKE, E. A.; BAUM, J. R. Entrepreneurial motivation. In: BAUM, J. R.; FRESE, M.; BARON, R. A. (Eds.). The psychology of entrepreneurship. The organizational frontiers. Mahwah, NJ: Lawrence Erlbaum Associates Publishers, 2007. p. 93-112.

LOPES JUNIOR, G. S.; SOUZA E. C. Atitude empreendedora em proprietários-gerentes de pequenas empresas: construção de um instrumento de medida. Revista Eletrônica de Administração, Porto Alegre, v. 11, n. 6, p. 1-21, 2005.

LUNA, I. N. Empreendedorismo e orientação profissional no contexto das transformações do mundo do trabalho. Revista Brasileira de Orientação Profissional, São Paulo, v. 13, n. 1, p. 111-116, 2012.

MACCALLUM, R. C. et al. On the practice of dichotomization of quantitative variables. Psychological Methods, Washington, v. 7, p. 19-40, 2002. 
MARKMAN, G. D.; BARON, R. A. Person-entrepreneurship fit: why some people are more successful as entrepreneurs than others. Human Resource Management Review, Athens, v. 13, n. 2, p. 281-301, 2003.

MATHIEU, C.; ST-JEAN, É. Entrepreneurial personality: the role of narcissism. Personality and Individual Differences, London, v. 55, n. 5, p. 527-531, 2013.

McCLELLAND, D. C. A sociedade competitiva: realização \& progresso social. Rio de Janeiro: Expressão e Cultura, 1972.

MINER, J. B. A psychological typology of successful entrepreneurs. Westport: Quorum Books, 1997a.

MINER, J. B. The expanded horizon for achieving entrepreneurial success. Organizational Dynamics, Lincoln, v. 25, n. 3, p. 54-67, 1997 b.

MINER, J. B. Testing a psychological typology of entrepreneurship using business founders. The Journal of Applied Behavioral Science, Silver Spring, v. 36, n. 1, p. 43-69, 2000.

MORAES, M. J.; HASHIMOTO, M.; ALBERTINE, T. Z. Perfil empreendedor: estudo sobre características empreendedoras de motoristas funcionários e autônomos do transporte rodoviário de cargas. Revista de Empreendedorismo e Gestão de Pequenas Empresas, Curitiba, v. 2, n. 1, p. 132-157, 2013.

MUELLER, S. L.; GOIĆ, S. Entrepreneurial potential in transition economies: a view from tomorrow's leaders. Journal of Developmental Entrepreneurship, Syracuse, v. 7, n. 4, p. 339-414, 2002.

MUELLER, S. L.; THOMAS, A. S. Culture and entrepreneurial potential: a nine country study of locus of control and innovativeness. Journal of Business Venturing, Indiana, v. 16, n. 1, p. 51-75, 2001.

NASSIF, V. M. J.; GHOBRIL, A. N.; SILVA, N. S. Understanding the entrepreneurial process: a dynamic approach. Brazilian Administration Review, Rio de Janeiro, v. 7, n. 2, p. 213-226, 2010. 
NICOLAOU, N.; SHANE, S.; CHERKAS, L.; SPECTOR, T. D. Opportunity recognition and the tendency to be an entrepreneur: A bivariate genetics perspective. Organizational

Behavior and Human Decision Processes, Seattle, v. 110, n. 2, p. 108-117, 2009.

NUNNALlY, J. C.; BERNSTEIN, I. H. Psychometric theory. 3. ed. Nova York: McGrawHill, 1995.

OBSCHONKA, M.; SILBEREISEN, R. K.; SCHMITT-RODERMUND, E. Entrepreneurial intention as developmental outcome. Journal of Vocational Behavior, Rootstown, v. 77, $\mathrm{n}$. 1, p. 63-72, 2010.

PARK, J. S. Opportunity recognition and product innovation in entrepreneurial hi-tech startups: a new perspective and supporting case study. Technovation, Ottawa, v. 25, p. 739-752, 2005.

PASQUALI, L. Escalas psicométricas. In: PASQUALI, L. (Org.). Instrumentação psicológica: fundamentos e práticas. Porto Alegre: Artmed, 2010. p. 116-135.

RAUCH, A.; FRESE, M. Born to be an Entrepreneur? Revisiting the personality approach to entrepreneurship. In: BAUM, J. R.; FRESE, M.; BARON, R. A. (Eds.). The psychology of entrepreneurship. The organizational frontiers. Mahwah, NJ: Lawrence Erlbaum Associates Publishers, 2007. p. 41-65.

ROTTER, J. B. Internal versus external control of reinforcement: a case history of a variable. American Psychologist, Washington, D.C., v. 45, n. 4, p. 489-493, 1990.

ROXAS, B.; CHADEE, D. Effects of formal institutions on the performance of the tourism sector in the Philippines: The mediating role of entrepreneurial orientation. Tourism Management, Hillcrest, v. 37, p. 1-12, 2013.

SANTOS, P. da C. F. Uma escala para identificar potencial empreendedor. 2008. 364 f. Tese (Doutorado em Engenharia de Produção) - Universidade Federal de Santa Catarina, Florianópolis, SC, Brasil, 2008.

SANTOS-ÁLVAREZ, V.; GARCÍA-MERINO, T. The role of the entrepreneur in identifying international expansion as a strategic opportunity. International Journal of Information Management, Dereham, v. 30, n. 6, p. 512-520, 2010.

SARASON, Y.; DEAN, T.; DILLARD, J. F. Entrepreneurship as the nexus of individual and opportunity: a structuration view. Journal of Business Venturing, v. 21, p. 286-305, 2006. 
SARASVATHY, S. D. The questions we ask and the questions we care about: reformulating some problems in entrepreneurship research. Journal of Business Venturing, Indiana, v. 19, n. 5, p. 707-717, 2004.

SARASVATHY, S. D. et al. Three views of entrepreneurial opportunity. In: ACS, Z. J.; AUDRETSCH, D. B. (Eds.). Handbook of entrepreneurship research: an interdisciplinary survey and introduction. New York: Springer, 2003. p. 141-160.

SARIS, W.; STRONKHORST, H. Causal modelling in nonexperimental research. Amsterdam: Sociometric Research Foundation, 1984.

SAY, J. B. Traité d'économie politique. Montreal: Éditions Weltanschauung, 2003. (publicado originalmente em 1832).

SCHMIDT, S.; BOHNENBERGER, M. C. Perfil empreendedor e desempenho organizacional. Revista de Administração Contemporânea, Rio de Janeiro, v. 13, n. 3, p. 450-467, 2009.

SCHUMPETER, J. A. The theory of economic development. New York: Oxford University Press, 1961.

SHANE, S. A general theory of entrepreneurship: The individual-opportunity nexus. Cheltenham: Edward Elgar, 2003.

SHANE, S. et al. Genetics, the Big Five, and the tendency to be self-employed. Journal of Applied Psychology, Washington, D.C., v. 95, n. 6, p. 1154-1162, 2010.

SHAPERO, A.; SOKOL, L. Social dimensions of entrepreneurship. In: KENT, C. A.; SEXTON, D. L.; VESPER, K. H. (Eds.). Encyclopedia of entrepreneurship. Englewood Cliffs: Prentice Hall, 1982.

SHENG, H. H. Modelos de financiamento baseados em relações pessoais: experiência de empreendedores chineses no Brasil. Revista de Administração Contemporânea, Rio de Janeiro, v. 12, n. 3, p. 741-761, 2008.

SOUZA, E. C. L. et al. Atitude empreendedora: validação de um instrumento de medida com base no modelo de resposta gradual da teoria da resposta ao item. Revista de Administração Mackenzie, São Paulo, v. 14, n. 5, p. 230-251, 2013. 
STUDART, R.; SUAZNÁBAR, C. Access to financing: A challenge to dynamic enterprise creation. In: KANTIS, H.; ANGELELLI, P.; KOENIG, V. M. (Eds.). Developing entrepreneurship: Experience in Latin America and worldwide. Washington: Inter-American Development Bank, 2005. pp. 89-100.

TABACHNICK, B. G; FIDELL, L. S. Using multivariate statistics. 5. ed. Boston: Pearson Education, 2007.

TAJEDDINI, K.; ELG, U.; TRUEMAN, M. Efficiency and effectiveness of small retailers: The role of customer and entrepreneurial orientation. Journal of Retailing and Consumer Services, Eindhoven, v. 20, n. 5, p. 453-462, 2013.

UCBASARAN, D.; WESTHEAD, P.; WRIGHT, M. The extent and nature of opportunity identification by experienced entrepreneurs. Journal of Business Venturing, Indiana, v. 24, n. 2, p. 99-115, 2009.

WU, S.; WU, L. The impact of higher education on entrepreneurial intentions of university students in China. Journal of Small Business and Enterprise Development, Birmingham, v. 15, n. 4, p. 752-774, 2008.

ZAHRA, S. A. et al. Globalization of social entrepreneurship opportunities. Strategic Entrepreneurship Journal, Chicago, v. 2, n. 2, p. 117-131, 2008. 


\section{Apêndice A \\ Inventário de Barreiras e Facilitadores ao Empreendedorismo}

INSTRUÇÕES. Por favor, leia atentamente a lista de comportamentos e características descritos a seguir, considerando seu conteúdo. Utilizando a escala de resposta abaixo, escreva um número dentro do colchete ao lado de cada item para indicar em que medida você considera que a frase lhe descreve.

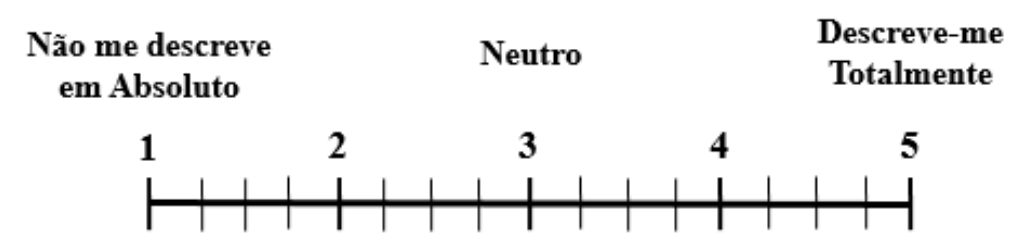

\begin{tabular}{lcc}
\hline Executo meu trabalho com paixão. & {[} & ] \\
\hline Sou uma pessoa inovadora. & {[} & ] \\
\hline Tenho um desejo de um dia abrir meu próprio negócio. & {[} & ] \\
\hline Sinto que possuo a habilidade de gerenciar pessoas. & {[} & ] \\
\hline Correr riscos em um negócio é algo inevitável, mas eu enfrentaria os riscos. & {[} & ] \\
\hline Sinto prazer em atividades que exigem imaginação/criatividade. & {[} & ] \\
\hline Consigo encontrar pessoas que possam facilitar a realização dos meus projetos. & {[} & ] \\
\hline Sinto prazer em fazer o meu trabalho de forma bem feita. & {[} & ] \\
\hline Geralmente, prefiro liderar os grupos que faço parte. & {[} & ] \\
\hline Eu abriria um negócio inovador apesar da insegurança. & {[} & ] \\
\hline Percebo uma facilidade em obter capital rapidamente. & {[} & ] \\
\hline Consigo detectar as possíveis oportunidades do mercado. & {[} & ] \\
\hline Sou capaz de motivar as pessoas a realizarem tarefas difíceis. & {[} & {[} \\
\hline Eu gostaria de investir em um negócio, se eu tivesse dinheiro e recursos. & {[} & {[} \\
\hline Sou corajoso e não tenho medo de abrir um negócio, mesmo com todo o risco. & {[} & ] \\
\hline Sei a quem posso recorrer para abrir um negócio. & {[} & ] \\
\hline Sou apaixonado por novas ideias. & {[} & ] \\
\hline Conheço pessoas que poderiam me ajudar com dinheiro para eu abrir meu negócio. & {[} \\
\hline Eu faria uma dívida de longo prazo para investir em uma oportunidade de negócio. & {[} \\
\hline Tenho a capacidade de obter lucro ao identificar uma oportunidade de negócio. & {[} \\
\hline Percebo a possibilidade de ter acesso à capital ou recursos para abrir um negócio. & {[} \\
\hline & {[} & {[} \\
\hline
\end{tabular}




\begin{tabular}{|c|c|c|}
\hline Tenho capacidade de estimular pessoas a trabalharem em grupo. & {[} & ] \\
\hline Sou uma pessoa com muita imaginação. & {[} & ] \\
\hline Tenho contatos que financiariam meu próprio negócio. & {[} & ] \\
\hline Tenho disposição a correr riscos relacionados aos negócios. & [ & ] \\
\hline Consigo identificar a oportunidade de um negócio lucrativo. & [ & ] \\
\hline Sinto-me envolvido pelo trabalho que realizo. & {[} & ] \\
\hline Acredito ser capaz de organizar as tarefas de um grupo. & {[} & ] \\
\hline Encaro as necessidades alheias (dos outros), como oportunidades de negócio. & {[} & ] \\
\hline Procuro manter redes de relacionamentos com as pessoas que sei que podem ser úteis para mim. & {[} & ] \\
\hline Sinto-me empolgado com a ideia de ter meu próprio negócio. & {[} & ] \\
\hline Apaixono-me pelos trabalhos que realizo. & {[} & ] \\
\hline Possuo uma rede de contatos que poderia me auxiliar na abertura de um negócio. & {[} & ] \\
\hline Caso fosse lucrativo, eu teria a intenção de iniciar um negócio. & {[} & ] \\
\hline Tenho como conseguir um empréstimo para abrir um novo negócio. & {[} & ] \\
\hline Sinto-me bem criando coisas novas. & {[} & ] \\
\hline Sinto-me atraído a identificar oportunidades de negócio. & {[} & ] \\
\hline Realizo com dedicação os meus trabalhos. & {[} & ] \\
\hline Tenho vontade de transformar minhas ideias em negócios. & {[} & ] \\
\hline $\begin{array}{l}\text { Se eu fosse abrir um negócio, saberia exatamente com quem eu entraria em contato para ser meu } \\
\text { sócio. }\end{array}$ & [ & ] \\
\hline
\end{tabular}

